\title{
O ESTADO DE NUTRIÇÃO DE CRIANÇAS INTERNADAS POR TÓDAS AS CAUSAS EM HOSPITAL ASSISTENCIAL DO MUNICAPIO DE S. PAULO
}

RoseṇBurg, O. - O estado de nutrição de crianças internadas pòr tôdas as causas em hospital assistencial do município de São Paulo. Rev. Saúde pribl., S. Paulo, 5:77-81, 1971.

RESUMo - Um estudo sôbre o estado de nutrição de 2.007 crianças entre 0 e 24 meses de idade, internadas num Hospital Assistencial do Município de São Paulo, revela que o percentual total de desnutridos corresponde a cêrca de $3 / 4$ da população observada. O percentual total de distróficos foi menor em 1963 do que em 1961, mas em 1969 ultrapassou o de 1963. O maior percentual de desnutridos em grau mais avançado ( $\left.D^{3}\right)$, que se encontrava, em 1961 e 1963, no primeiro semestre do segundo ano de vida, deslocou-se em 1969, para o segundo semestre do primeiro ano de vida.

UnITERMos - Desnutrição*; Hospital Infantil *; Hospital Assistencial.

\section{INTRODUCAO}

Os estudos até agora realizados em Hospitais Assistenciais sôbre o estado de nutrição da criança hospitalizada, referem-se apenas ao levantamento dos casos mais graves, em que a desnutrição se apresenta como causa primária da internação, ou como entidade clínica suficientemente definida para figurar como diagnóstico associado ou secundário.

0 presente estudo teve como objetivo uma pesquisa sôbre o estado de nutrição de crianças internadas por tôdas as causas em um Hospital Assistencial da Municipalidade de São Paulo (2), sem levar em consideração o diagnóstico ou diag- nósticos, definitivos ou provisórios, registrados nos prontuários hospitalares.

\section{POPULACAO E METODOS}

Os estudos foram realizados sôbre 2.007 crianças de 0 a 24 meses de idade, internadas no $10^{\circ}$ semestre dos anos de 1961 e 1963 e durante todo o ano de 1969.

Da ficha preenchida no momento da admissão, foi anotado o pêso obtido na ocasião. Em seguida, levando em consideração idade, pêso e sexo, os pacientes foram classificados sob 4 itens a) nor-

Recebido para publicação em 22-4-1971.

(1) Do Departamento de Prática de Saúde Pública. Disciplina de Higlene da Crianca da Faculdade de Saúde Pública da USP. Av. Dr. Arnaldo, 715 - São Paulo, SP - Brasil. Resumo de parte da monografia apresentada à Faculdade de Saúde Pública, a 8-2-71, para a obtencăo de Mestrado.

(2) Hospital Infantll Menino Jesus. 
ROSENBURG, O. - O estado de nutrição de criancas internadas por tôdas as causas em hospital assistencial no municipio de São Paulo. Rev. Saúde pübl., S. Paulo, 5:77-81, 1971.

mais; b) distróficas em $10^{\circ}$ grau $\left(D_{1}\right)$; c) distróficas em $2 .^{\circ}$ grau $\left(D_{2}\right) ;$ e d) distróficas em 3.0 grau $\left(\mathrm{D}_{3}\right)$.

$O$ critério de normalidade em relação ao pêso, obedeceu aos padrões de AzEVEDo ${ }^{1}$. Os diferentes graus de desnutrição correspondem ao conceito de GoMEZ ${ }^{2}$, respectivamente:

- Distrofia de 1.0 grau ou $D_{1}$ : perda de pêso entre 10 e $25 \%$ do pêso teórico para a idade e sexo.

- Distrofia de 2.0 grau ou $\mathrm{D}_{2}$ : perda de pêso entre 25 e $40 \%$ do pêso teórico.

- Distrofia de $30^{\circ}$ grau ou $\mathrm{D}^{3}$ : perda de pêso igual ou superior a $40 \%$ do pêso teórico.

Foram excluídas do estudo:

1) Crianças sôbre as quais houve menção de prematuridade.

2) Crianças com pêso de nascimento inferior a $2.200 \mathrm{~g}$, ainda que com periodo de gestação normal.

TABELA 1

Criancas de 0 a 24 meses: Distribuição semestral segundo o estado de nutrição Hospital Menino Jesus - 1961 - 1.0 semestre

\begin{tabular}{|c|c|c|c|c|c|}
\hline Idade & N & $D_{1}$ & $\mathrm{D}_{2}$ & $\mathrm{D}_{\mathbf{z}}$ & Total \\
\hline $0-6$ meses & $\begin{array}{c}64 \\
25,8 \%\end{array}$ & $\begin{array}{c}61 \\
25 \%\end{array}$ & $\begin{array}{c}58 \\
23,6 \%\end{array}$ & $\begin{array}{c}61 \\
25 \%\end{array}$ & $\begin{array}{c}244 \\
61,61 \%\end{array}$ \\
\hline $6-12$ meses & $\begin{array}{c}22 \\
28,1 \%\end{array}$ & $\begin{array}{c}19 \\
24 \%\end{array}$ & $\begin{array}{c}22 \\
27,7 \%\end{array}$ & $\begin{array}{c}16 \\
20,2 \%\end{array}$ & $\begin{array}{c}79 \\
19,94 \%\end{array}$ \\
\hline $12-18$ meses & $\begin{array}{c}6 \\
15,3 \%\end{array}$ & $\begin{array}{c}8 \\
20,6 \%\end{array}$ & $\begin{array}{c}12 \\
30,7 \%\end{array}$ & $\begin{array}{c}13 \\
33,3 \%\end{array}$ & $\begin{array}{c}39 \\
9,84 \%\end{array}$ \\
\hline $18-24$ meses & $\begin{array}{c}9 \\
26,4 \%\end{array}$ & $\begin{array}{c}14 \\
41,1 \%\end{array}$ & $\begin{array}{c}6 \\
17,6 \%\end{array}$ & $\underset{14,7 \%}{5}$ & $\begin{array}{c}34 \\
8,58 \%\end{array}$ \\
\hline Total & $\begin{array}{c}101 \\
25,50 \%\end{array}$ & $\begin{array}{c}102 \\
27,75 \%\end{array}$ & $\begin{array}{c}98 \\
24,74 \%\end{array}$ & $\begin{array}{c}95 \\
23,98 \%\end{array}$ & $\begin{array}{c}396 \\
99,97 \%\end{array}$ \\
\hline
\end{tabular}

T A B E A 2

Estado de nutrição (1.0 e 2.0 anos de vida) Hospital Menino Jesus - 1961 - 1.0 semestre

\begin{tabular}{|c|c|c|c|}
\hline Idade & Normais & $\begin{array}{c}\text { Desnutridas } \\
\left(D_{1}+D_{2}+D_{3}\right)\end{array}$ & Total \\
\hline 1. ano $^{\circ}$ & $\begin{array}{c}86 \\
26,63 \%\end{array}$ & $\begin{array}{c}237 \\
73,37 \%\end{array}$ & $\begin{array}{c}323 \\
100 \%\end{array}$ \\
\hline $2 .^{\circ}$ ano & $\begin{array}{c}15 \\
20,55 \%\end{array}$ & $\begin{array}{c}58 \\
79,45 \%\end{array}$ & $\begin{array}{c}73 \\
100 \%\end{array}$ \\
\hline Total & $\begin{array}{c}101 \\
25,50 \%\end{array}$ & $\begin{array}{c}295 \\
74,49 \%\end{array}$ & $\begin{array}{c}396 \\
99,99 \%\end{array}$ \\
\hline
\end{tabular}

RESULTADOS

$1961-1.0^{\circ}$ semestre

$O$ percentual total de crianças desnutridas nos três graus foi de 74,49 , contra 25,50 de normais.

$O$ percentual total de crianças em $D_{1}$ $(27,75)$ ultrapassou ligeiramente os percentuais de $\mathrm{D}_{2}(24,74)$ e de $\mathrm{D}_{3}(23,98)$. Mas considerados os grupos etários isoladamente, vemos que $D_{2}$ predominou no grupo de 6-12 meses $(27,7)$, enquanto 
ROSENBURG, O. - O estado de nutriçăo de criancas internadas por tódas as causas em hospital assistencial no municiplo de Sāo Paulo. Rev. Saúde públ., S. Paulo, 5:77-81, 1971.

$\mathrm{D}_{3}$ predominou no grupo de $12-18$ meses $(33,3)$ e se igualou a $D_{1}$ no grupo de 0 a 6 meses (25).

Resultados mais detalhados encontramse na Tabela 1, na qual, tanto quanto nas Tabelas 3 e 5 , foi adotada uma distribuição etária semestral, que facilita a interpretação dos dados, uma vez que, na distribuição mensal, o número de casos é, às vêzes, muito reduzido.

Considerados o $1 .^{\circ}$ e o $2 .^{\circ}$ anos de vida separadamente (Tabela 2), vemps que o percentual total de desnutridos em todos predominou no grupo de 6-12 meses $(28,9)$ enquanto $D_{3}$ predominou no grupo de 12-18 meses $(26,9)$.

Examinados separadamente o $10^{\circ}$ e o $2 .^{\circ}$ anos de vida (Tabela 4 ), vemos que o percentual total de desnutridos em todos os graus foi maior no $20^{\circ}$ ano de vida $(73,46)$ do que no $10^{\circ}$ ano de vida $(68,59)$.

0 percentual total de crianças desnutridas $(69,66)$ foi menor do que em 1961 $(74,49)$.

TABELA 3

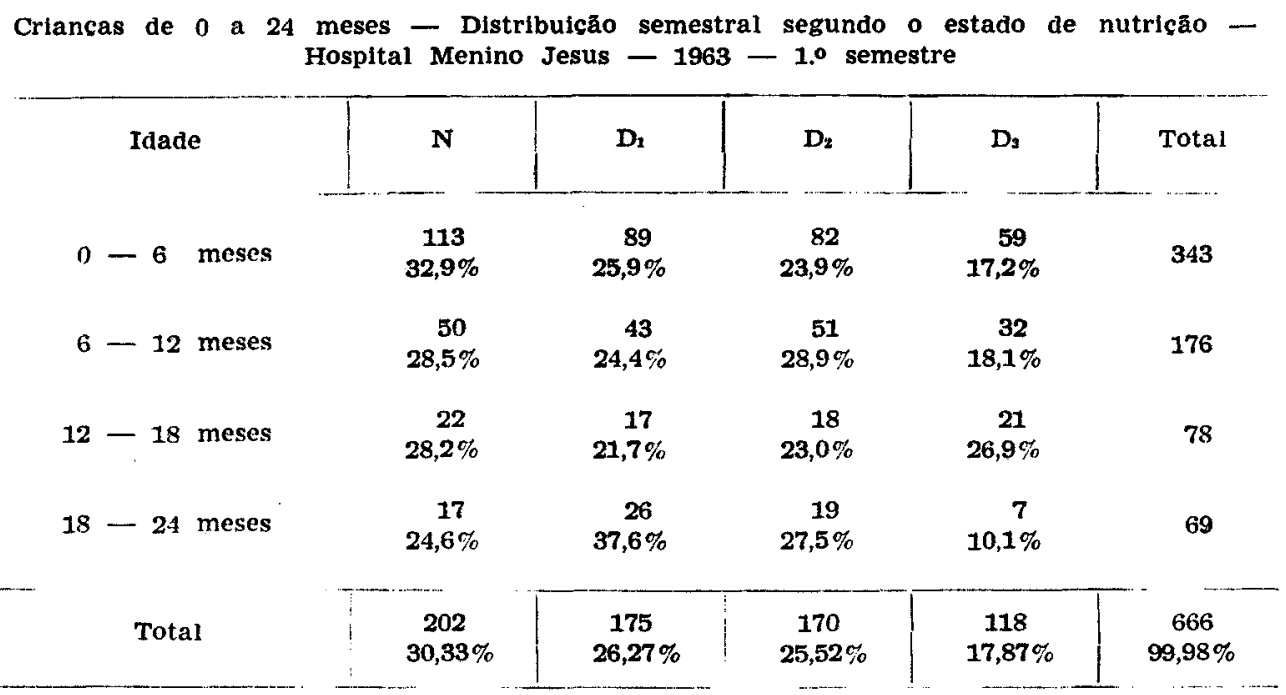

os graus foi maior no $2 .^{\circ}$ ano de vida $(79,45)$ do que no $1 .^{\circ}$ ano de vida $(73,37)$.

\section{$1963-10^{\circ}$ semestre (Tabela 3)}

O percentual total de crianças desnutridas em todos os graus foi de 69,66 contra 30,33 de crianças normais.

$O$ percentual total de crianças em $D_{1}$ $(26,27)$ foi ligeiramente maior do que em $D_{2}(25,52)$ e maior do que em $D_{3}$ $(17,86)$. Mas considerados os grupos etários isoladamente, verifica-se que $D_{2}$
TABELA 4

Estado de nutrição (1.0 e 2.0 anos de vida) Hospital Menino Jesus - 1963 - 1.0 semestre

\begin{tabular}{|c|c|c|c|}
\hline Idade & Normais & $\begin{array}{c}\text { Desnutridas } \\
\left(D_{1}+D_{2}+D_{3}\right)\end{array}$ & Total \\
\hline $1 .^{\circ}$ ano & $\begin{array}{c}163 \\
31,41 \%\end{array}$ & $\begin{array}{c}356 \\
68,59 \%\end{array}$ & $\begin{array}{c}519 \\
100 \%\end{array}$ \\
\hline $2 .^{\circ}$ ano & $\begin{array}{c}39 \\
26,54 \%\end{array}$ & $\begin{array}{c}108 \\
73,46 \%\end{array}$ & $\begin{array}{c}147 \\
100 \%\end{array}$ \\
\hline Total & $\begin{array}{c}202 \\
30,33 \%\end{array}$ & $\begin{array}{c}464 \\
69,66 \%\end{array}$ & $\begin{array}{c}666 \\
99.98 \%\end{array}$ \\
\hline
\end{tabular}


ROSENBURG, O. - O estado de nutrição de criancas internadas por tódas as causas em hospital assistencial no municipio de São Paulo. Rev. Saúd públ., S. Paulo, 5:77-81, 1971.

T A BE L A 5

Criancas de 0 a 24 meses - Distribulção semestral segundo o estado de nutriçāo Hospital Menino Jesus - 1969 - $1 .^{\circ}$ e $2 .^{\circ}$ semestres

\begin{tabular}{|c|c|c|c|c|c|}
\hline Idade & $\mathbf{N}$ & $D_{1}$ & $\mathrm{D}_{2}$ & $\mathbf{D}_{\mathbf{2}}$ & Total \\
\hline $0-6$ meses & $\begin{array}{c}178 \\
32,60 \%\end{array}$ & $\begin{array}{c}131 \\
23,99 \%\end{array}$ & $\begin{array}{c}145 \\
26,35 \%\end{array}$ & $\begin{array}{c}92 \\
18,84 \%\end{array}$ & $\begin{array}{c}546 \\
\mathbf{5 7 , 7 7 \%}\end{array}$ \\
\hline 6 - 12 meses & $\begin{array}{c}32 \\
17,97 \%\end{array}$ & $\begin{array}{c}45 \\
25,28 \%\end{array}$ & $\begin{array}{c}47 \\
26,40 \%\end{array}$ & $\begin{array}{c}\mathbf{5 4} \\
\mathbf{3 0 , 3 3} \%\end{array}$ & $\begin{array}{c}178 \\
18,33 \%\end{array}$ \\
\hline $12-18$ meses & $\begin{array}{c}29 \\
20,86 \%\end{array}$ & $\begin{array}{c}\mathbf{5 0} \\
\mathbf{3 5}, \mathbf{9 7} \%\end{array}$ & $\stackrel{39}{39,05 \%}$ & $\begin{array}{c}21 \\
15,10 \%\end{array}$ & $\begin{array}{c}139 \\
14,70 \%\end{array}$ \\
\hline $18-24$ meses & $\begin{array}{c}17 \\
20,70 \%\end{array}$ & $\begin{array}{c}32 \\
\mathbf{3 9 , 0 2} \%\end{array}$ & $\begin{array}{c}23 \\
28,04 \%\end{array}$ & $\begin{array}{c}10 \\
12,19 \%\end{array}$ & $\begin{array}{c}82 \\
8,67 \%\end{array}$ \\
\hline Total & $\begin{array}{c}256 \\
27,08 \%\end{array}$ & $\begin{array}{c}258 \\
27,30 \%\end{array}$ & $\begin{array}{c}254 \\
26,87 \%\end{array}$ & $\begin{array}{c}177 \\
18,73 \%\end{array}$ & $\begin{array}{c}945 \\
99,98 \%\end{array}$ \\
\hline
\end{tabular}

\section{9 (Tabela 5)}

O percentual total de crianças desnutridas em todos os graus foi de 72,91 contra 27,08 de crianças normais.

$O$ percentual total de crianças em $D_{1}$ $(27,30)$ foi ligeiramente maior do que em $D_{2}(26,87)$ e maior do que em $D_{3}$ $(18,73)$.

Considerados os grupos etários isoladamente, verifica-se que $D_{2}$ predominou no grupo de 0 a 6 meses $(26,35)$ enquanto $\mathrm{D}_{3}$ predominou no grupo de 6-12 meses $(30,33)$.

TABELA 6

Estado de nutriçáo (1.0 e 2.0 anos de vida) Hospital Menino Jesus 1969 - $10^{\circ}$ e $2 .^{\circ}$ semestres

\begin{tabular}{|c|c|c|c|}
\hline Idade & Normais & $\begin{array}{c}\text { Desnutridas } \\
\left(D_{1}+D_{2}+D_{2}\right)\end{array}$ & Total \\
\hline 1.0 ano & $\begin{array}{c}210 \\
29,01 \%\end{array}$ & $\begin{array}{c}\mathbf{5 1 4} \\
\mathbf{7 0 , 9 9 \%}\end{array}$ & $\begin{array}{c}724 \\
100 \%\end{array}$ \\
\hline $2 .^{\circ}$ ano & $\begin{array}{c}46 \\
20,82 \%\end{array}$ & $\begin{array}{c}175 \\
79,18 \%\end{array}$ & $\begin{array}{c}221 \\
100 \%\end{array}$ \\
\hline Total & $\begin{array}{c}256 \\
27,08 \%\end{array}$ & $\begin{array}{c}689 \\
72,91 \%\end{array}$ & $\begin{array}{c}945 \\
99,98 \%\end{array}$ \\
\hline
\end{tabular}

Examinados em separado o $10^{\circ}$ e $20^{\circ}$ anos de vida (Tabela 6 ) nota-se que $o$ percentual total de desnutridos em todos os graus foi maior no $2 .^{\circ}$ ano de vida $(79,18)$ do que no $1 .^{\circ}$ ano $(70,99)$.

$O$ percentual total de crianças desnutridas em todos os graus $(72,91)$ foi maior do que em $1963(69,66)$ e menor do que em $1961(74,49)$.

\section{COMENTARIOS}

Nos três anos estudados, o percentual total de crianças desnutridas em todos os graus ultrapassou amplamente o percentual de crianças normais, correspondendo a cêrca de $3 / 4$ do total de casos observados.

0 percentual total de crianças distróficas em todos os graus foi menor em 1963, segundo ano de estudo, do que em 1961. Mas em 1969 sobrepujou o de 1963, ainda que permanecendo inferior ao de 1961. Tal fato demonstra uma deteriorização no estado de nutrição relativa ao último ano da pesquisa, e não confirma aquela melhora que a diferença para menos, observada entre os dois primeiros anos, poderia levar a pressu. por. 
ROSENBURG, O. - 0 estado de nutriçáo de crianças internadas por tódas as causas em hospital assistencial no municipio de São Paulo. Rev. Sarids puibl., S. Paulo, 5:77-81, 1971.

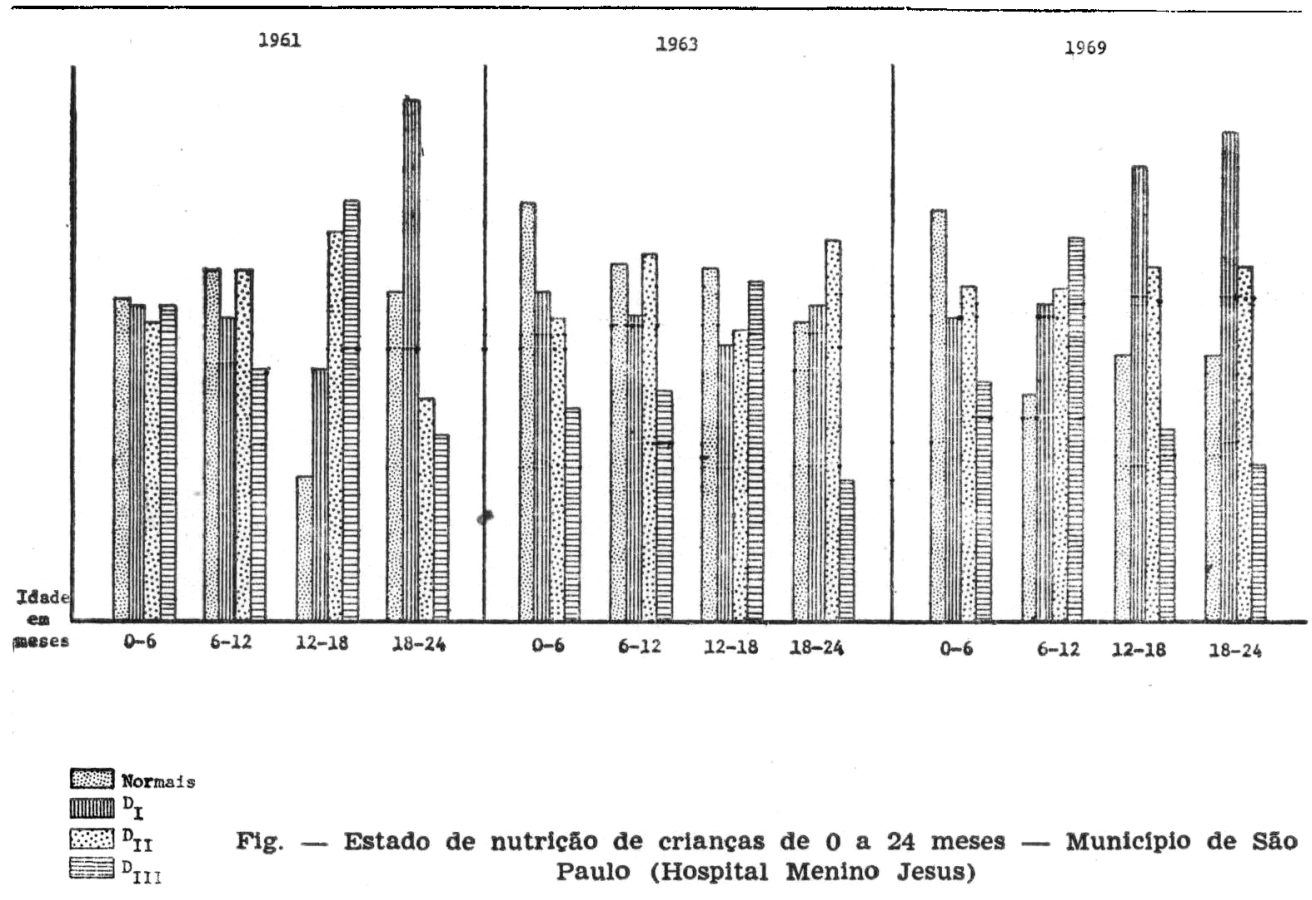

Nos 3 anos considerados, o percentual total em crianças em $D_{1}$ foi ligeiramente maior do que em $D_{2}$ e $D_{3}$. Mas no estudo particularizado dos diferentes graus de desnutrição nos diferentes grupos etários, além dos fatos já citados, deve-se chamar a atenção sôbre o comportamento da forma mais grave de desnutrição $\left(D_{3}\right)$, ou seja, daquela que com maior frequência leva ao óbito. Em 1961 e 1963, o maior percentual de crianças em distrofia de $3 .^{\circ}$ grau encontra-se no grupo etário de 12-18 meses, ou seja, no $10^{\circ}$ semestre do $2 .^{\circ}$ ano de vida. Esse grupo se encontra numa fase que sucede imediatamente o desmame total da criança. Em 1969, verifica-se que o maior percentual de crianças em $\mathrm{D}_{3}$ deslocou-se para o grupo etário de 6-12 meses, portanto, para o $2 .^{\circ}$ semestre do $10^{\circ}$ ano de vida.

É digna de nota essa modificação, constatada em 1969, em desfavor do $10^{\circ}$ ano de vida.

Tais fenômenos podem ser melhor vizualizados na Figura.
Rosensurg, O. - [The nutritional status in children interned irrespective of diagnosis in an assistencial Hospital in the city of São Paulo - Brazill. Rev. Saúde pribl., S. Paulo, 5:77-81, 1971.

Summary - The nutritional status of 2.007 children, between zero to 24 months, admitted to an Assistential Hospital of $\mathbf{S}$. Paulo City irrespective of diagnosis, was studied. The total percentage of distrophics in all grades reached almost $3 / 4$ of the supervisioned children. The percentual decrease of undernourished children observed in 1963 did not persist in 1969. The greatest percentage of children in $D_{3}$ which in 1961 and 1963 was found in the first semester of the 2nd year of life, displaced itself in 1969 to the 2nd semester of the first year of life.

UNITERMS - Malnutrition *; Hospitals (Pediatrics) *; Hospital, Assistencial *.

\section{REFERENCIAS BIBLIOGRAFICAS}

1. AZEVEDO, E. - Contribuiøão para o estudo do peso e da estatura das creancas em são Paulo. São Paulo, 1932. [Tese - Faculdade de Medicina USPJ.

2. GOMEZ, F. - Desnutrición. Bol. méd. Hos. Int., México, 3:543, 1946. 